\title{
Structure, magnetism, and magnetostrictive properties of mechanically alloyed $\mathrm{Fe}_{81} \mathrm{Ga}_{19}$
}

\author{
P. Taheri ${ }^{1,2^{*}}$, R. Barua ${ }^{1,2}$, J. Hsu ${ }^{1,4}$, M.Zamanpour ${ }^{1,3}$, Y. Chen ${ }^{1,2}$, V.G. Harris ${ }^{1,2,3,{ }^{*}}$ \\ ${ }^{1}$ Center for Microwave Magnetic Materials and Integrated Circuits, Northeastern University, Boston, MA \\ ${ }^{2}$ Department of Electrical and Computer Engineering, Northeastern University, Boston, MA \\ ${ }^{3}$ Department of Chemical Engineering, Northeastern University, Boston, MA \\ ${ }^{4}$ Walt Whitman High School, Bethesda, MD
}

*Corresponding author E-mail address: taheri.p@husky.neu.edu; harris@ece.neu.edu

In this work, structure-magnetic property correlations and the magnetostrictive response of mechanically alloyed powders of composition $\mathrm{Fe}_{81} \mathrm{Ga}_{19}$ were investigated using a variety of structural and magnetic probes. X-ray diffraction analysis of the as-milled powders suggests the presence of a chemicallydisordered body-centered cubic phase. Thermal annealing of powder compacts results in formation of a secondary phase that demonstrates the cubic ordered $\mathrm{L}_{2}$ crystal structure. Magnetostriction measurements indicate that the magnetoelastic properties of the polycrystalline $\mathrm{Fe}_{81} \mathrm{Ga}_{19}$ compacts can be tailored by increasing the milling time duration followed by an anneal of the as-milled powders at $900^{\circ} \mathrm{C}$ for 2 hours in an $\mathrm{Ar}$ gas environment $\left(\mathrm{O}_{2}<5 \mathrm{ppm}\right)$. Under those conditions, the room temperature saturation magnetostriction was measured to be as high as $41 \mathrm{ppm}$ at a low magnetic field of $H_{a p p} \sim 10$ Oe. The magnetostrictive behavior of the mechanically alloyed $\mathrm{Fe}_{81} \mathrm{Ga}_{19}$ powders was found to be comparable with FeGa samples prepared by other non-equilibrium powder processing techniques. Based upon the results presented here, it is proferred that ball-milling offers a cost-effective pathway towards realizing large volumes of FeGa alloys having moderate values of magnetostriction.

(C) 2015. This manuscript version is made available under the Elsevier user license http://www.elsevier.com/open-access/userlicense/1.0/ 


\section{INTRODUCTION}

Functional magnetic materials systems that demonstrate large magnetostriction play an important role in a wide range of applications, including sonar systems [1], force, displacement and torque sensors [2], [3], microelectromechanical actuators, and vibration energy harvesting and vibration control devices [4]. To this end, it is important to note that one of the most promising magnetostrictive materials hitherto is Galfenol, $\mathrm{Fe}_{1-\mathrm{x}} \mathrm{Ga}_{\mathrm{x}}(\mathrm{Galfenol})$ [5] - an inexpensive, corrosion resistant [6], machinable alloy that in single crystal form exhibits high tensile strength $(\sim 500 \mathrm{MPa})$ [7], and a moderate magnetostriction $\left(3 / 2 \lambda_{100} \sim\right.$ $350 \mathrm{ppm}$ ) under a low magnetic field of $\sim 100$ Oe [7]. Studies conducted by Kellogg et al. indicate that the magnetomechanical properties of these intermetallic alloys show limited variation over a temperature range $-20-80{ }^{0} \mathrm{C}$ and therefore it is understood that this materials system can withstand large shock loads in harsh operating environments [7]. It is well known that the excellent functional properties of this system are closely correlated with their microstructural and crystallographic properties [8]. In particular, the large magnetostriction in $\mathrm{Fe}_{1-\mathrm{x}} \mathrm{Ga}_{\mathrm{x}}$ near $x=19$ is ascribed to local short-range interactions between the $\mathrm{Ga}$ atoms along specific crystallographic directions in the disordered body-centered cubic (bcc) $\alpha-\mathrm{Fe}$ structure [9]. Further, it is commonly believed that the decrease in magnetostriction in FeGa compounds, as the alloy composition approaches $\mathrm{x}=25$, may arise from the formation of the ordered $\mathrm{D} 0_{3}[10]$ and $\mathrm{L1}_{2}$ [11] phases.

Over the past two decades, a variety of sample synthesis and processing techniques have been explored to provide a means for controlling the structural properties and hence the magnetostrictive behavior of this alloy system [8]. To this end, it is critical to realize that though single crystals are an ideal starting point for characterizing and modeling the functional response of the FeGa system, textured polycrystalline forms of this material are likely to be more commercially viable [7] [12]. While single crystals of FeGa have been synthesized using either the Bridgman method or the optical zone melting method [13], textured polycrystalline samples (ingots, sheets, rods and ribbons) have been fabricated using a variety of methods including arc-melting followed by directional solidification, directional solidification using the modified Bridgman technique [7], cold rolling [14], melt-spinning [15], 
combinatorial sputtering [16], and powder processing involving agitation at elevated temperature in the presence of a magnetic field [17]. A consolidated table summarizing the experimental values of saturation magnetostriction of FeGa alloys synthesized using different processing techniques is provided as Table 1 with relevant references. It is intriguing to note that in spite of extensive investigations in this materials system, only one study in the literature has focused on the non-equilibrium sample synthesis technique, mechanical alloying [18].

Mechanical alloying is a simple non-equilibrium sample processing method that involves cold welding, fracturing, and re-welding of powder particles in a high-energy ball mill [19]. Powders prepared by mechanical alloying are promising as engineered materials as they provide a convenient form for the fabrication of magnetostrictive alloy-polymer matrix composites for magnetostrictive applications. Gaudet et al. were the first to synthesize mechanically alloyed FeGa powders and it was found that in the as-milled state the samples show the presence of a disordered body-centered cubic (bcc) A2 phase with no indication of any secondary phases [18]. Annealing studies conducted by this same research group showed that $\mathrm{DO}_{3}$ and $\mathrm{L1}_{2}$-like ordering of the $\mathrm{Ga}$ on the lattice occurs at elevated temperatures and thus it is construed that decrease in the short range Ga clustering of the lattice sites may lower the magnetostrictive performance of mechanically alloyed powders, relative to that of corresponding bulk polycrystalline samples [18]. Since Gaudet et al.'s study does not characterize the magnetostrictive performance of their samples and to date, the relationship between the crystallographic, microstructural and magnetoelastic properties of mechanically alloyed FeGa powders remains unclear, the present study attempts to address this obvious need.

Here, we present a detailed report on the preparation and properties of mechanically alloyed $\mathrm{Fe}_{81} \mathrm{Ga}_{19}$. It is well known that ball milling process conditions (example: milling atmosphere, ratio of ball to powder mass, milling speed, milling ball size, and milling duration) are critical to achieving high quality mechanically alloyed powders [19]. Therefore in this work, the structural, magnetic and magnetostrictive properties of mechanically alloyed as-milled powders and annealed compact samples, were examined as a function of milling time. Results obtained in this work provide pathways for tailoring 
the microstructure and magnetoelastic properties of $\mathrm{FeGa}$ compounds for potential magnetostrictive applications.

\section{EXPERIMENTAL METHODS:}

Iron - gallium alloys of the nominal composition $\mathrm{Fe}_{81} \mathrm{Ga}_{19}$ were mechanically alloyed by a high-energy ball mill operating at room temperature. Starting materials employed in these experiments included: metal Fe powders of purity $99.9 \%$ with an average effective diameter of $\sim 10 \mu \mathrm{m}$ and metal Ga of purity 99.99\%. In the first step, Fe and Ga were mixed and mechanically alloyed by using a high-energy ball mill for durations from 1 to 15 hours. Stainless steel balls were used as the grinding medium. A combination of ten - $10 \mathrm{~mm}$ diameter balls (36 grams each in mass) and ten $-6 \mathrm{~mm}$ diameter balls $(9$ grams each in mass) were used in a ball-to-powder mass ratio of 10:1. Toluene was used as process control agent. After milling, the powders were mixed with 5\% poly-vinyl alcohol (PVA) and pressed in a $6 \mathrm{~mm}$ die set under 1.5 metric tons of pressure. The compacted samples were annealed in an argon gas atmosphere at $\mathrm{T}=900{ }^{\circ} \mathrm{C}$ hours for 2 hours. The chemical composition and homogeneity of the powdered sample were confirmed by energy-dispersive X-ray spectroscopy in a scanning electron microscope (SEM-EDS, Hitachi S4800). X-ray diffraction patterns were obtained at room temperature for all samples using a standard $\mathrm{Cu} \mathrm{K} \alpha$ radiation source $(\lambda=1.54 \AA)$. Bragg peaks obtained from the XRD pattern were fitted to a Pseudo-Voigt fitting function and a least-squares fit was applied to estimate lattice parameters [20]. Line broadening analysis using the Scherrer method was employed to estimate the crystallite size of the mechanically alloyed FeGa powders [20]. The magnetic behavior of the samples were investigated at room temperature in magnetic fields up to $\mathrm{H}=1.2 \mathrm{~T}$ using a vibrating sample magnetometer (Model: 7400 Series). Room temperature magnetostrictive properties of the annealed compacted samples were measured with the magnetic field $\left(H_{a p p}\right.$ in the range, 0-1.2 T) parallel to the sample plane using a traditional quarter-bridge technique with the strain gauge (Vishay micro-measurements P3 strain indicator) positioned atop the compact. 


\section{RESULTS AND DISCUSSION}

\subsection{Structural \& Morphological Properties}

Figure 1 shows X-ray diffraction patterns of annealed iron gallium milled mixtures of nominal composition $\mathrm{Fe}_{81} \mathrm{Ga}_{19}$ together with the pattern collected from a high purity iron powder (as a crystallographic bcc reference standard) after milling times of 1 to 15 hours. The single phase FeGa bcclike structure defined as an A2 structure from examination of the phase diagram [5], is identified by the three strongest peaks indexed to (110), (200), and (211) planes. As is seen, the polycrystalline $\mathrm{Fe}_{81} \mathrm{Ga}_{19}$ samples show a slight [110]-preferred crystallographic texture. Also, in Fig. 1, one observes a slight shift of the (110) reflection to larger d-spacing consistent with an increase in the lattice parameter to larger values with increased milling duration. After 6 hours, additional Bragg reflections corresponding to the cubic ordered $\mathrm{L}_{2}$ phase are observed and a decrease in the lattice parameter of the A2 phase is measured. Figure 2 shows the evolution of the lattice parameters of the crystallographic phases found in the mechanically alloyed $\mathrm{Fe}_{81} \mathrm{Ga}_{19}$ samples. It is critical to note that the $\mathrm{L}_{2}$ phase was not detected in the $\mathrm{Fe}_{81} \mathrm{Ga}_{19}$ powders in the as-milled state, irrespective of milling time. Nonetheless, the $\mathrm{A} 2 \rightarrow \mathrm{A} 2+\mathrm{L}_{2}$ structural transition is consistent with the equilibrium FeGa phase diagram [8], and as such, it is construed that in the samples under consideration in this work, prolonged ball milling followed by thermal annealing generates sufficient heat to drive the microstructure from the $\mathrm{A} 2$ phase field into the $\mathrm{A} 2+\mathrm{L} 1_{2}$ region of the phase diagram. It is worthwhile to mention that formation of the $\mathrm{L}_{2}$ phase has also been reported in annealed FeGa samples synthesized by other non-equilibrium methods, namely by rapidsolidification techniques such as melt-spinning [15],and gas [17] atomization.

Figure 3 is a composite figure of several SEM micrographs of milled powder samples, before and after heat treatment. The annealed samples shown here were lightly etched using a dilute nitric acid solution to reveal the finer details of the microstructure. Images of the pure iron powder (ball-milled for a period of 1 hour under similar conditions as the other sample mixtures) serve as a reference for the $\mathrm{Fe}_{81} \mathrm{Ga}_{19}$ samples. Iron, being considerably more malleable than the materials under study, behaves considerably differently than FeGa. Overall, the particle morphology of iron can be described as 
uniformly sized nodules with rounded and smooth surfaces. Upon heat treatment at $900 \mathrm{C}$ for 2 hours, one observes considerable grain growth via Ostwald ripening with large grains retaining smooth surfaces. In sharp contrast to pure Fe, the particle morphology of ball milled iron gallium mixtures are more faceted a signature of cold welding during the high-energy ball milling process. The sample milled for 15 hours has a larger average particle size ( $>5 \square \mathrm{m}$ ) than that milled for 6 hours (3-5 $\square \mathrm{m}$ ) - a feature that may be attributed to increased toughness due to dislocation pile-up caused by cold welding. Notwithstanding the large particle size, the crystallite size remains comparable for all milled samples at $\sim 40-50 \mathrm{~nm}$ as determined by Scherrer analysis of the [110] diffraction peak.

Examination of the morphology of these samples following heat-treatment and etching shows a striking difference. In the annealed samples, one sees larger particles suggesting aggregation. Etching reveals a fine structure on the particle surface suggesting an embedded nanostructure. The sample milled for 6 hours shows a honeycomb-like microstructure on the surface of the etched aggregates. The honeycomb character of the sample microstructure becomes more pronounced upon milling for longer time periods. This observation is tentatively ascribed to preferential etching of either the $\mathrm{L} 1_{2}$ or A2 phases relative to the other. Overall, the conclusions drawn from the SEM images shown in Figure 2 are consistent with the XRD data that demonstrate an increase in the $\mathrm{L} 1_{2}$ phase concentration with increase in milling time.

\subsection{Magnetic Properties}

The field-dependent magnetic behavior of the mechanically alloyed powder samples in as-milled as well as annealed state were examined at room temperature. Figures $4(a)$ and $4(b)$ shows the evolution of $H_{c}$ and $M_{s}$ as a function of milling time. In considering the saturation magnetization values, one sees a clear trend of decreasing magnetization with increasing milling time, consistent with the appearance of the secondary $\mathrm{L}_{2}$ FeGa phase. Though it remains to be confirmed, it is speculated in the FeGa literature that the intrinsic saturation magnetization value of the ferromagnetic $\mathrm{L}_{2} \mathrm{FeGa}$ phase is significantly lower that of the A2 phase [21]. Heat treatment provides additional thermal energy for formation of the chemically disordered FeGa A2 phase and consequently an overall increase is observed in the $M_{s}$ of the 
annealed samples, relative to that of the corresponding as-milled powders (See Figure 4(a)).

Trends in the coercivity of the mechanically alloyed $\mathrm{Fe}_{81} \mathrm{Ga}_{19}$ powders, shown in Figure 4(b), are in agreement with the changing microstructure of the sample with increasing milling times and heattreatments. As such, the overall $H_{c}$ of the as-milled samples are larger than that of their annealed counterparts. Upon post-annealing, all samples demonstrate coercive field values ranging from 20-30 Oe, with one exception in that at $\mathrm{t}=15 \mathrm{~h}$ where co-existence of the $\mathrm{A} 2$ and the $\mathrm{L} 1_{2}$ FeGa phase is noted. These results suggest that the crystallite size of the A2 FeGa phase $(D \sim 50 \mathrm{~nm}$ as determined from the Scherrer equation) is above the single domain particle size where the coercivity depends upon both domain wall interactions within single crystallites and domain wall interactions that encompass clusters of crystallites [20].

\subsection{Magnetostrictive Properties}

This study focuses on the magnetostrictive properties of annealed compacts of mechanically alloyed, $\mathrm{Fe}_{81} \mathrm{Ga}_{19}$ powders only. Figure 5 shows the evolution of the magnetostrictive coefficient $(\square)$ of the pure Fe powder and annealed FeGa powder compacts as a function of applied magnetic field and milling time. Here, Fe serves as a reference standard and its behavior is found to be in good agreement with that reported in literature (magnetostrictive coefficient, $\square_{s}=-8 \mathrm{ppm}$ [20]). The magnetostrictive coefficient increases as a function of ball milling time reaching a maximum value, $\sim 41 \mathrm{ppm}$, for the $6 \mathrm{~h}$ milled sample. In agreement with previous reports in the literature that demonstrate a reduction in magnetostrictive performance in FeGa systems that exhibit coexistence of the A2 and $\mathrm{L}_{2}$ phases [17], Figure 5 clearly indicates that the sample milled for 15 hours shows a dramatic reduction in $\lambda_{s}$ relative to that of other samples milled for shorter times. The experimental trends shown in Figure 5 are in agreement with the X-ray diffraction data that indicate that the sample milled for 6 hours has the longest ball mill duration prior to the onset of the $\mathrm{L}_{2}$ phase (see Figures 1 and 2). The lattice parameter of this sample is closest to the A2 phase, which is known to have a high magnetostrictive value $\left(\mathrm{a}_{\mathrm{Fe} 81 \mathrm{Ga} 19} \sim 0.291\right.$ $\AA$ [10]). It is also critical to observe that the $t=6$ hours sample has the highest slope approaching 
saturation magnetostriction $(0.0038 \mathrm{ppm} / \mathrm{Oe})$ signaling its superior potential for application, as this would require a small bias field to reach maximum sensing performance.

Following the work of Cullity and Graham [7], who first reported the relationship between magnetostriction and magnetization for polycrystalline Fe samples could be described by a power law relationship of the form $-=3 / 2\left(\frac{M}{M_{s}}\right)^{2}$, we plot the normalized magnetostriction as a function of the square of normalized magnetization in Fig. 6. In the high-field region, the plot of $\lambda$ vs. $\mathrm{M}^{2}$ may be reasonably approximated by a line. The reason for this behavior is that the magnetization of most specimens changes almost entirely by domain rotation in this high-field region, just as the magnetization of stressed specimens change by spin rotation over the range of $M=0$ to $M_{S}[20]$.

\section{CONCLUSION}

Mechanical alloying of Fe and Ga powders were investigated by high-energy ball milling under different milling durations. X-ray diffraction revealed that high energy milling for time periods up to 6 hours converts the elemental constituents to an alloy dominated by the chemically disordered A2 phase. Prolonged milling and subsequent annealing beyond this point leads to the appearance of the cubic ordered $\mathrm{L}_{2}$ phase, which is consistent with the equilibrium phase diagram. A maximum magnetostriction of $\sim 41$ ppm was observed in $\mathrm{Fe}_{81} \mathrm{Ga}_{19}$ composites containing annealed powders (see Figure 5). This magnetostriction value is comparable to those measured from polycrystalline FeGa alloys prepared by other processing techniques, namely gas atomization and cold rolling (See Table 1). It has been proposed by many theoretical and experimental studies that the many-fold increase in FeGa magnetostriction, relative to that of pure $\mathrm{Fe}$, may be due to emergence of short-range ordering of Ga atoms in the [100] crystallographic direction $[7,15,22]$. It is thus conjectured that the magnetostriction effect observed in mechanically alloyed FeGa powders may be enhanced by applying an external magnetic field during heat treatment. Future work to this end is planned. Overall, this study demonstrates the feasibility of large- 
scale production of $\mathrm{FeGa}$ polycrystalline alloys powders by a simple and cost-effective mechanical alloying technique.

ACKNOWLEDGEMENTS: Funding from the US Army under grant W911NF-10-2-0098, sub award 15-215456-03-00 is gratefully acknowledged. 


\section{REFERENCES:}

[1] R. Jain, Design and Packaging of an Iron- Gallium (Galfenol) Nanowire Acoustic Sensor for Underwater Applications, 2007.

[2] M.J. Parsons, S. Datta, C. Mudivarthi, S.M. Na, A. Flatau, \&lt;title\&gt;Torque sensing using rolled galfenol patches\&lt;/title\&gt;, 6933 (2008) 693314-693314-9. doi:10.1117/12.776576.

[3] L. Weng, B. Wang, M.J. Dapino, Y. Sun, L. Wang, B. Cui, Relationships between magnetization and dynamic stress for Galfenol rod alloy and its application in force sensor, J. Appl. Phys. 113 (2013) 17A917. doi:10.1063/1.4795328.

[4] V. Berbyuk, Vibration energy harvesting using Galfenol-based transducer, 8688 (2013) $86881 \mathrm{~F}$. doi:10.1117/12.2009812.

[5] S. Guruswamy, N. Srisukhumbowornchai, a. E. Clark, J.B. Restorff, M. Wun-Fogle, Strong, ductile, and low-field-magnetostrictive alloys based on Fe-Ga, Scr. Mater. 43 (2000) 239-244. doi:10.1016/S1359-6462(00)00397-3.

[6] a. E. Clark, K.B. Hathaway, M. Wun-Fogle, J.B. Restorff, T. a. Lograsso, V.M. Keppens, et al., Extraordinary magnetoelasticity and lattice softening in bcc Fe-Ga alloys, J. Appl. Phys. 93 (2003) 8621-8623. doi:10.1063/1.1540130.

[7] R.A. Kellogg, A.B. Flatau, T. a Lograsso, Development and modelong of iron-gallium alloys, Dissertation. (2003).

[8] J. Atulasimha, A.B. Flatau, A review of magnetostrictive iron-gallium alloys, Smart Mater. Struct. 20 (2011) 043001. doi:10.1088/0964-1726/20/4/043001.

[9] S. Rafique, Magnetic anisotropy of FeGa alloys, J. Appl. Phys. 95 (2004) 6939. doi:10.1063/1.1676054.

[10] T. a. Lograsso, E.M. Summers, Detection and quantification of D03 chemical order in Fe-Ga alloys using high resolution X-ray diffraction, Mater. Sci. Eng. A. 416 (2006) 240-245.

doi:10.1016/j.msea.2005.10.035.

[11] N. Srisukhumbowornchai, S. Guruswamy, Influence of ordering on the magnetostriction of Fe27.5 at. \% Ga alloys, J. Appl. Phys. 92 (2002) 5371. doi:10.1063/1.1508426.

[12] V. Sundararaghavan, Multiscale Modeling of Polycrystalline Magnetostrictive Alloy Galfenol: Microstructural Model, Proc. 1st World Congr. Integr. Comput. Mater. Eng. (2011) 57-62. doi:10.1002/9781118147726.ch7.

[13] E.M. Summers, T. a. Lograsso, J.D. Snodgrass, J.C. Slaughter, \&lt;title\&gt;Magnetic and mechanical properties of polycrystalline Galfenol\&lt;/title\&gt;, 5387 (2004) 448-459. doi:10.1117/12.539781. 
[14] E.M. Summers, R. Meloy, S.-M. Na, Magnetostriction and texture relationships in annealed galfenol alloys, J. Appl. Phys. 105 (2009) 07A922. doi:10.1063/1.3067849.

[15] J. Zhang, T. Ma, M. Yan, Effect of heat treatment on structure, magnetization and magnetostriction of Fe81Ga19 melt-spun ribbons, Phys. B Condens. Matter. 404 (2009) 41554158. doi:10.1016/j.physb.2009.07.185.

[16] R. a Dunlap, N.C. Deschamps, R.E. Mar, S.P. Farrell, Mössbauer effect studies of Fe ${ }_{100-x} \mathrm{Ga}_{x}$ films prepared by combinatorial methods, J. Phys. Condens. Matter. 18 (2006) 4907-4920. doi:10.1088/0953-8984/18/20/015.

[17] J. Li, X. Gao, J. Zhu, J. Jia, M. Zhang, The microstructure of Fe-Ga powders and magnetostriction of bonded composites, Scr. Mater. 61 (2009) 557-560. doi:10.1016/j.scriptamat.2009.04.019.

[18] J.M. Gaudet, T.D. Hatchard, S.P. Farrell, R. a. Dunlap, Properties of Fe-Ga based powders prepared by mechanical alloying, J. Magn. Magn. Mater. 320 (2008) 821-829. doi:10.1016/j.jmmm.2007.08.029.

[19] C. Suryanarayana, Mechanical alloying and milling, Prog. Mater. Sci. 46 (2001) 1-184. doi:10.1016/S0079-6425(99)00010-9.

[20] G. a. Novak, A. a. Colville, A practical interactive least-squares cell-parameter program using an electronic spreadsheet and a personal computer, Am. Mineral. 74 (1989) 488-490. http://www.minsocam.org/ammin/AM74/AM74_488.pdf.

[21] B.D. Cullity, C.D. Graham, Introduction to magnetic materials, 2009. doi:10.1016/S13697021(09)70091-4.

[22] C.J. Quinn, P.J. Grundy, N.J. Mellors, The structural and magnetic properties of rapidly solidified Fe100-xGax alloys, for 12.8 $\leq x \leq 27.5$, J. Magn. Magn. Mater. 361 (2014) 74-80. doi:10.1016/j.jmmm.2014.02.004.

[23] J.. Cullen, a. . Clark, M. Wun-Fogle, J.. Restorff, T.. Lograsso, Magnetoelasticity of Fe-Ga and FeAl alloys, J. Magn. Magn. Mater. 226-230 (2001) 948-949. doi:10.1016/S0304-8853(00)00612-0.

[24] A.E. Clark, M. Wun-Fogle, J.B. Restorff, T. a. Lograsso, Smart Materials-Fundamentals and Applications. Magnetostrictive Properties of Galfenol Alloys Under Compressive Stress., Mater. Trans. 43 (2002) 881-886. doi:10.2320/matertrans.43.881.

[25] K. Walters, S. Busbridge, S. Walters, Magnetic properties of epoxy-bonded iron-gallium particulate composites, Smart Mater. Struct. 22 (2013) 025009. doi:10.1088/09641726/22/2/025009.

[26] J. Atulasimha, A.B. Flatau, E. Summers, Characterization and energy-based model of the magnetomechanical behavior of polycrystalline iron-gallium alloys, Smart Mater. Struct. 16 (2007) 1265-1276. doi:10.1088/0964-1726/16/4/039. 
[27] J.I. Hong, V.C. Solomon, D.J. Smith, F.T. Parker, E.M. Summers, a. E. Berkowitz, One-step production of optimized Fe-Ga particles by spark erosion, Appl. Phys. Lett. 89 (2006) 142506. doi:10.1063/1.2358825. 


\section{LIST OF TABLES:}

Table 1. Summary of FeGa alloy processing techniques with corresponding room temperature saturation magnetostriction values

\section{LIST OF FIGURES:}

Figure 1. X-ray diffraction patterns of annealed $\mathrm{Fe}_{81} \mathrm{Ga}_{19}$ samples. The indexed Bragg reflections correspond to the disordered body-centered cubic (bcc) structure. Additional peaks corresponding to the cubic ordered $\mathrm{L}_{2}$ phase is observed in samples milled for time periods greater than 6 hours.

Figure 2. Lattice parameter trends in the disordered body-centered cubic A2 phase found in the mechanically alloyed $\mathrm{Fe}_{81} \mathrm{Ga}_{19}$ samples. The * symbol represents samples where the A2 phase coexists with the ordered cubic $\mathrm{L}_{2}$ phase. The lattice parameter of the $\mathrm{L}_{2}$ phase found in the $\mathrm{Fe}_{81} \mathrm{Ga}_{19}$ powders milled for 15 hours is a 3.709 $\pm 0.005 \AA$.

Figure 3. SEM micrograph of mechanically alloyed $\mathrm{Fe}$ and $\mathrm{Fe}_{81} \mathrm{Ga}_{19}$ powder samples, before and after heat treatment. Here, Fe serves as a reference standard.

Figure 4. Evolution of the saturation magnetization (left) and coercity (right) of the as-milled and annealed $\mathrm{Fe}_{81} \mathrm{Ga}_{19}$ powders as a function of milling time duration

Figure 5. Plot of magnetostriction as a function of applied magnetic field in annealed $\mathrm{Fe}_{81} \mathrm{Ga}_{19}$ composites comprising of $5 \mathrm{wt} \% \mathrm{PVA}$ and mechanically alloyed powders. The milling time duration was varied between 1 to 15 hours.

Figure 6. Plot of normalized magnetostriction $\left(\lambda / \lambda_{s}\right)$ as a function of the square of normalized magnetization $\left(M / M_{s}\right)$ 


\section{TABLES AND FIGURES}

\section{Table 1. Summary of FeGa alloy processing techniques with corresponding room temperature saturation magnetostriction values 3}

\begin{tabular}{|c|c|c|c|}
\hline Synthesis Technique & Form of FeGa & $\begin{array}{l}\text { Magnetostriction, } \lambda \\
\text { (ppm) }\end{array}$ & Reference \\
\hline Bridgeman Technique & Single crystal ([100] oriented) & $\lambda_{100} \sim 400$ & Clark et al. [23] \\
\hline $\begin{array}{l}\text { Suction casting followed by low } \\
\text { energy blade milling }\end{array}$ & $\begin{array}{l}\text { Epoxy-bonded composites containing } \\
\text { polycrystalline powder }\end{array}$ & $\lambda_{\mathrm{s}} \sim 360 \mathrm{ppm}$ & Walters et al.[24] \\
\hline Zone melting (FSZM) & $\begin{array}{l}\text { Pollycrystalline rods (strong [100] and } \\
{[310] \text { texture) }}\end{array}$ & $\lambda_{s} \sim 200$ & Atulasimha et al. [25] \\
\hline $\begin{array}{l}\text { Modified Bridgeman Technique } \\
\text { (directionally solidified) }\end{array}$ & $\begin{array}{l}\text { Polycrystalline rods ((high degree of } \\
\langle 110\rangle \text { texture }))\end{array}$ & $\lambda_{s} \sim 170$ & $\begin{array}{l}\text { Kellog, Ph.D. } \\
\text { thesis[7] }\end{array}$ \\
\hline Melt spinning & $\begin{array}{l}\text { Pollycrystalline ribbons (high degree of } \\
\text { [100] texture) }\end{array}$ & $\lambda_{s} \sim 130$ & Zhang et al. [15] \\
\hline Hot rolling followed by annealing & Polycrystalline disks & $\lambda_{\|-\perp} \sim 95^{*}$ & $\begin{array}{l}\text { Kellog, Ph.D. } \\
\text { thesis[7] }\end{array}$ \\
\hline $\begin{array}{l}\text { Warm rolling followed by } \\
\text { annealing }\end{array}$ & Polycrystalline disks & $\lambda_{\|-\perp} \sim 70^{*}$ & $\begin{array}{l}\text { Kellog, Ph.D. } \\
\text { thesis[7] }\end{array}$ \\
\hline $\begin{array}{l}\text { Suction casting followed by } \\
\text { annealing }\end{array}$ & Polycrystalline sphere & $\lambda_{s} \sim 70$ & Walters et al. [24] \\
\hline $\begin{array}{l}\text { Gas atomization followed by } \\
\text { annealing in the presence of a } \\
\text { magnetic field }\end{array}$ & $\begin{array}{l}\text { Epoxy-bonded composites containing } \\
\text { polycrystalline powder }\end{array}$ & $\lambda_{s} \sim 64$ & Li et al. [17] \\
\hline $\begin{array}{l}\text { Sintering followed by annealing in } \\
\text { the presence of a magnetic field }\end{array}$ & Polycrystalline powder & $\lambda_{\mathrm{s}} \sim 60$ & Kellog et al. [7] \\
\hline Spark erosion & $\begin{array}{l}\text { Epoxy-bonded composites containing } \\
\text { polycrystalline powder }\end{array}$ & $\lambda_{\mathrm{s}} \sim 53$ & Hong et al. [26] \\
\hline Mechanical alloying & $\begin{array}{l}\text { PVA-bonded composites containing } \\
\text { polycrystalline powder }\end{array}$ & $\lambda_{\mathrm{s}} \sim 41$ & Current work \\
\hline Cold rolling followed annealing & Pollycrystalline disks & $\lambda_{\perp} \sim 30-35^{*}$ & Kellog et al. [7] \\
\hline Hot Forging & Polycrystalline disks & $\lambda_{\|-\perp} \sim 18-35^{*}$ & $\begin{array}{l}\text { Kellog, Ph.D. } \\
\text { thesis[7] }\end{array}$ \\
\hline
\end{tabular}

* Magnetostriction of disk shaped specimens were measured perpendicular and parallel to the long axis of the samples. 


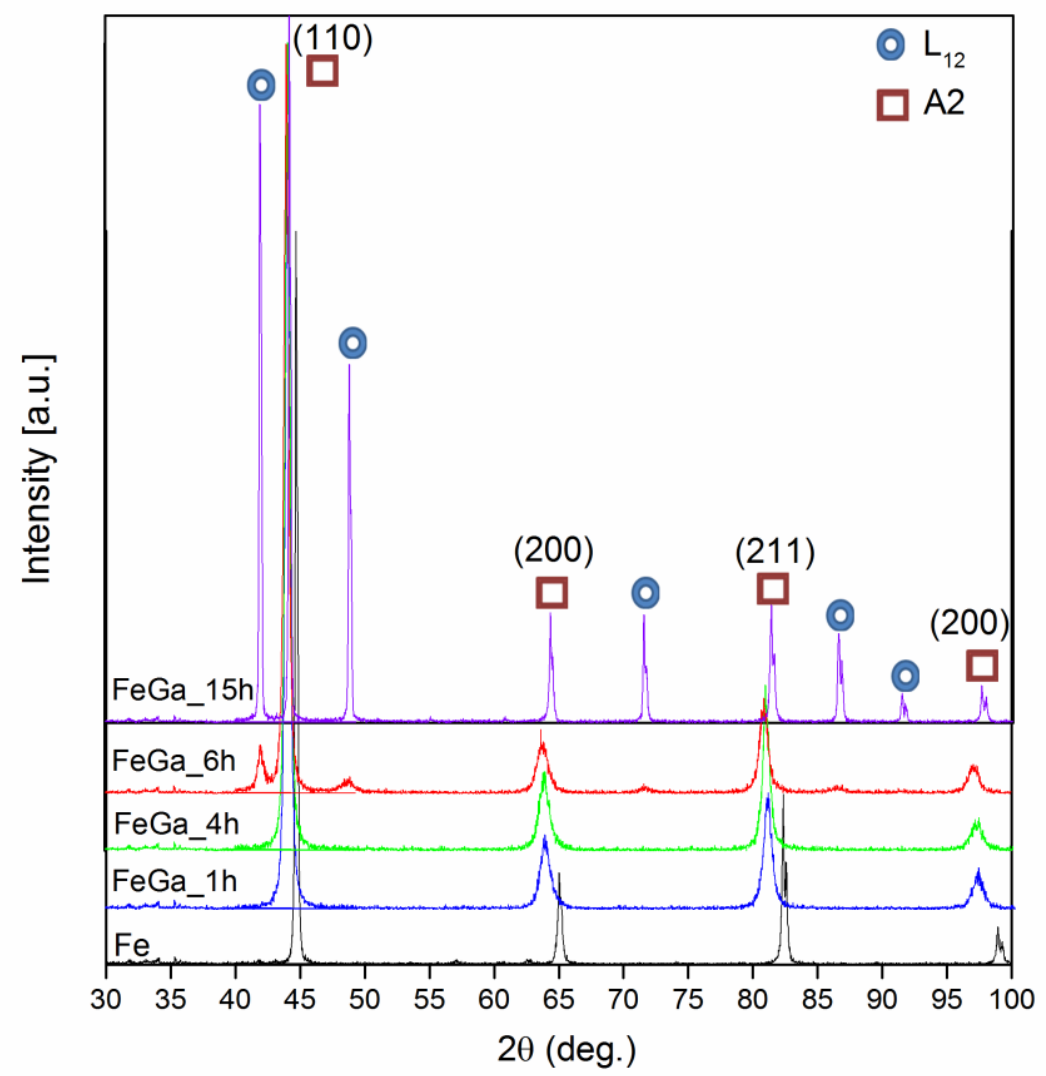

Figure 1. X-ray diffraction patterns of annealed $\mathrm{Fe}_{81} \mathrm{Ga}_{19}$ samples. The indexed Bragg reflections correspond to the disordered body-centered cubic (bcc) structure. Additional peaks corresponding to the cubic ordered $\mathrm{L}_{2}$ phase is observed in samples milled for time periods greater than 6 hours. 


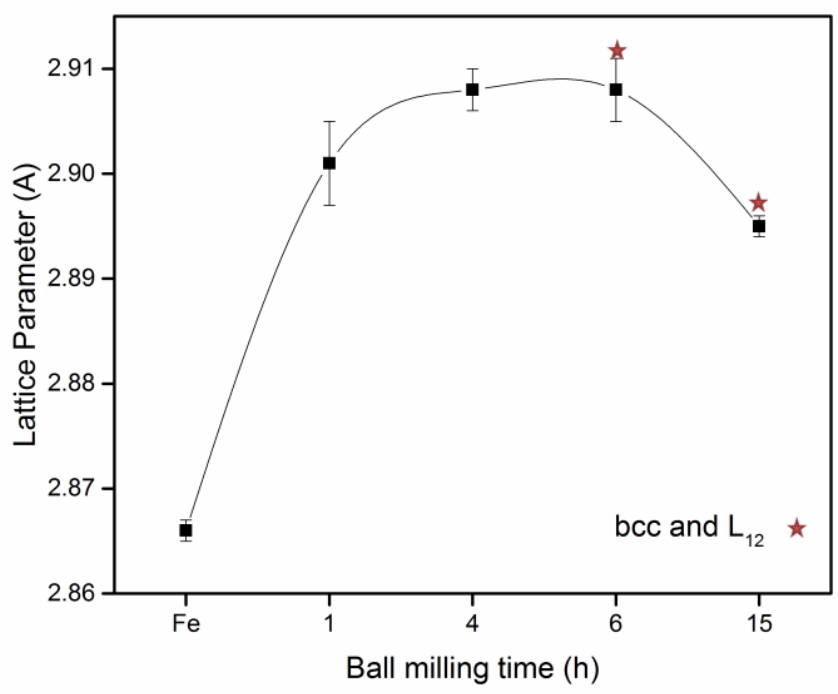

Figure 2. Lattice parameter trends in the disordered body-centered cubic A2 phase found in the mechanically alloyed $\mathrm{Fe}_{81} \mathrm{Ga}_{19}$ samples. The * symbol represents samples where the A2 phase coexists with the ordered cubic $\mathrm{L1}_{2}$ phase. The lattice parameter of the $\mathrm{L1}_{2}$ phase found in the $\mathrm{Fe}_{81} \mathrm{Ga}_{19}$ powders milled for 15 hours is a 3.709 $\pm 0.005 \AA$.
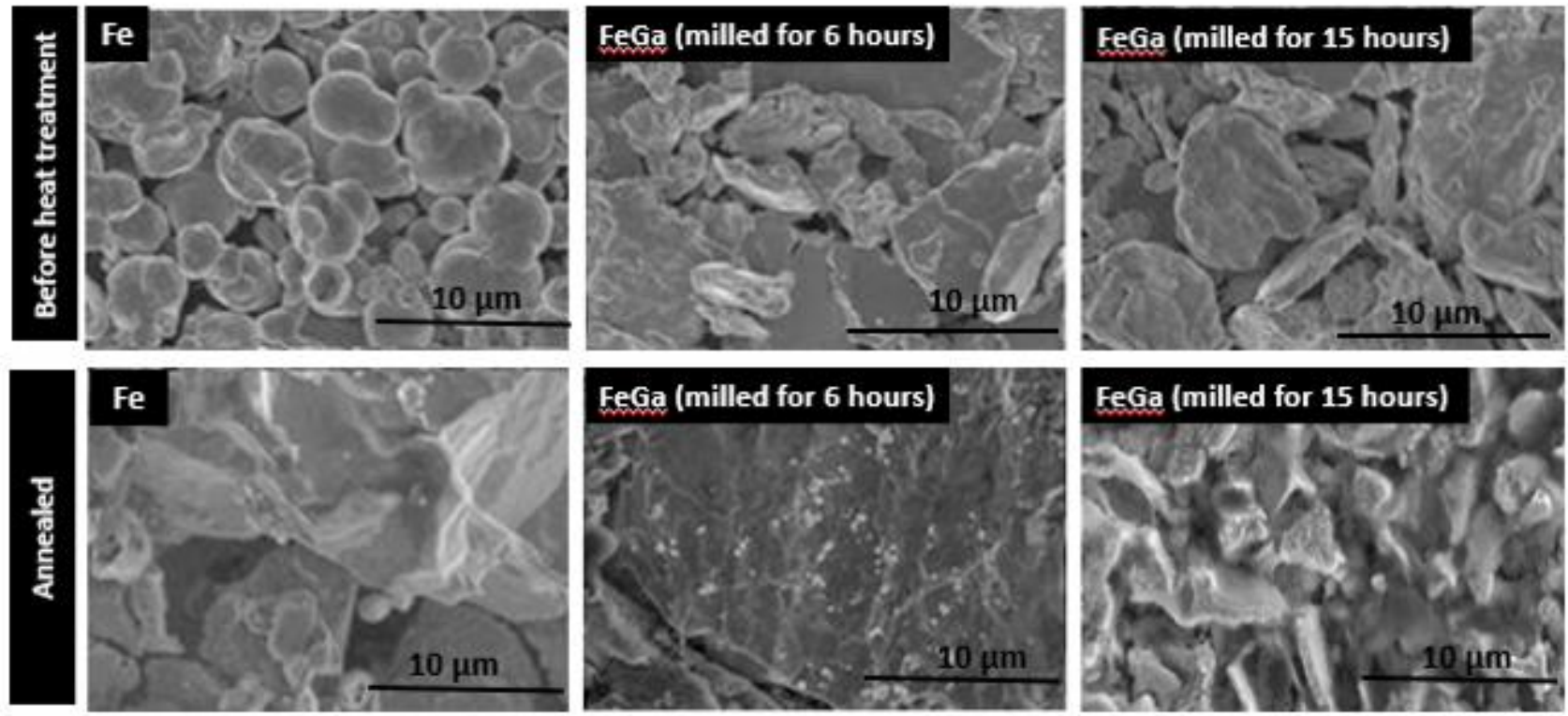

Figure 3. SEM micrograph of mechanically alloyed $\mathrm{Fe}$ and $\mathrm{Fe}_{81} \mathrm{Ga}_{19}$ powder samples, before and after heat treatment. Here, Fe serves as a reference standard. 

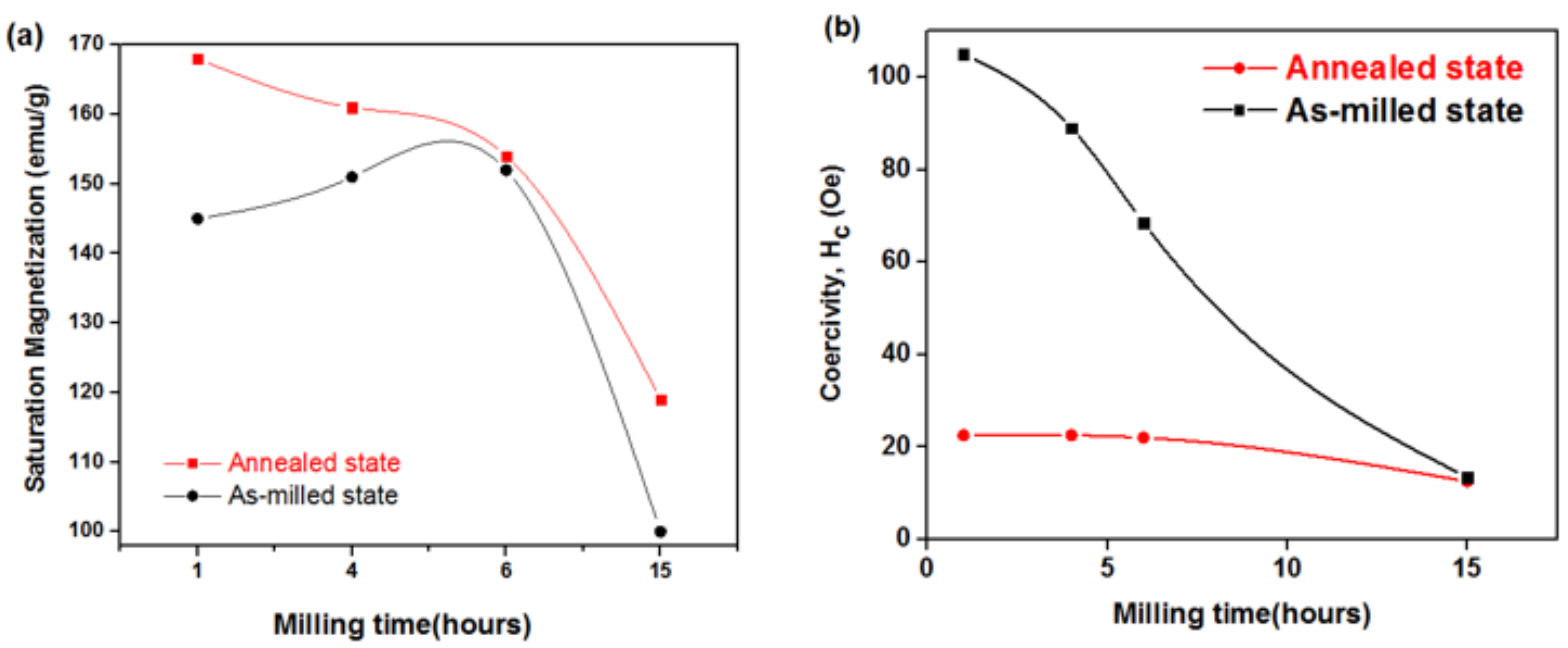

Figure 4. Evolution of the saturation magnetization (left) and coercity (right) of the asmilled and annealed $\mathrm{Fe}_{81} \mathrm{Ga}_{19}$ powders as a function of milling time duration

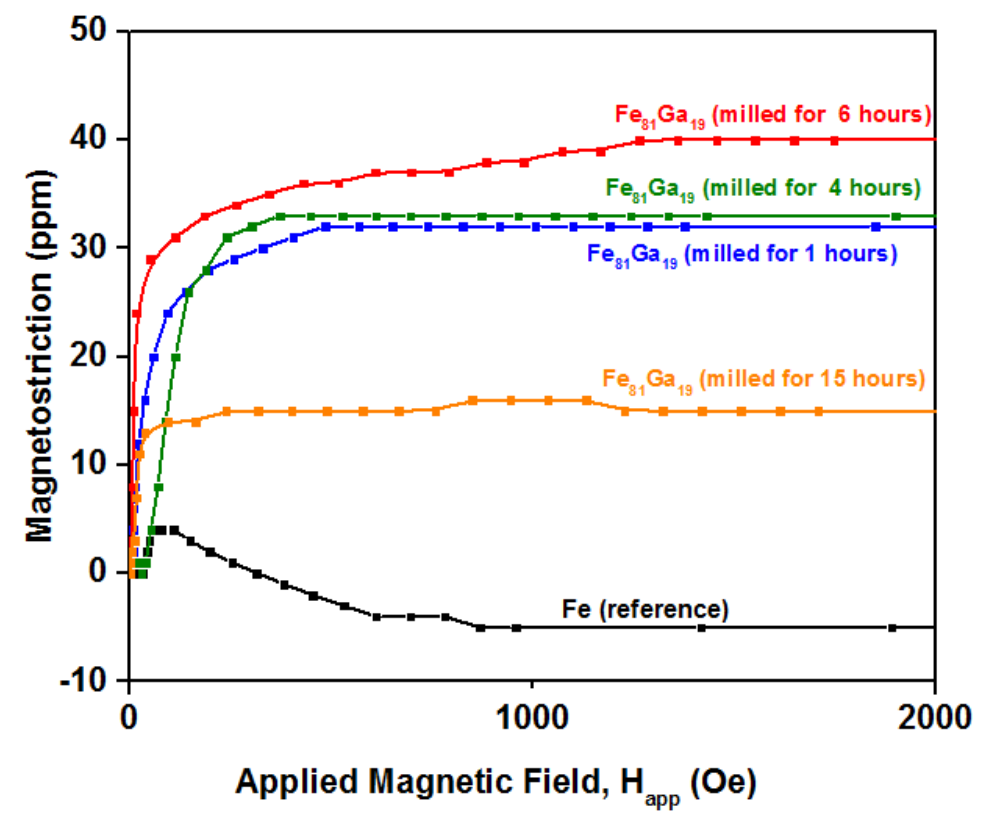

Figure 5. Plot of magnetostriction as a function of applied magnetic field in annealed $\mathrm{Fe}_{81} \mathrm{Ga}_{19}$ composites containing mechanically alloyed powders milled for different time durations ranging from 1 to 15 hours. 


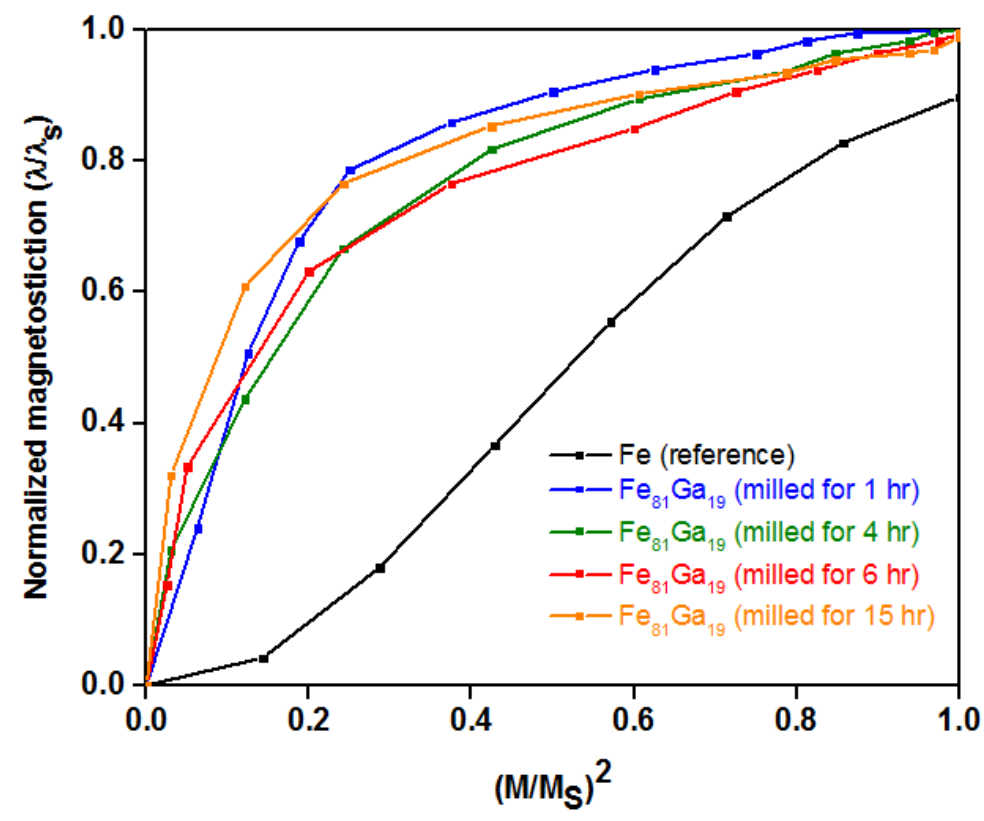

Figure 6. Plot of normalized magnetostriction $\left(\lambda / \lambda_{s}\right)$ as a function of the square of normalized magnetization $\left(M / M_{s}\right)$ 